\title{
INTEGRAR Y EXCLUIR (COMUNIÓN Y EXCOMUNIÓN EN EL MEDIEVO)
}

\author{
POR \\ Emilio Mitre FernándeZ \\ Universidad Complutense, Madrid*
}

\section{RESUMEN}

La excomunión medieval, en sus diversas manifestaciones tiene unas raíces bíblicas, patrísticas y canónicas. A lo largo del Medievo se aplicará en diversas situaciones y a toda clase de personas aunque las aplicadas por papas a monarcas sean las mas llamativas. En la Baja Edad Media aumentarán las críticas a este expediente por parte de destacados autores (Marsilio de Padua y Guillermo de Ockham a la cabeza) y por parte de diversos organismos políticos: vg. Las Cortes castellanas.

Palabras Clave: Excomunión en la Edad Media. Implicaciones religiosas y políticas.

\section{INTEGRATE AND EXCLUDE (COMMUNION AND EXCOMMUNICATION IN THE MIDDLE AGES)}

\begin{abstract}
The medieval excommunication, in its various manifestations, has biblical, patristic and canonical roots. During the Medieval Ages it is applicable to several situations and to all the people but the most known is that applied to monarchs by the Popes. In the late Middle Ages increased the critics to this expedient, made by relevant authors (Marsilius of Padua or William of de Ockham) and politic organisms: vg. The Cortes of Castile.
\end{abstract}

KEY Words: Medieval Excommunication. Religious and politic implications.

${ }^{*}$ El presente artículo se basa en la lección final (La Iglesia ante el Medievo: comunión y excomunión) pronunciada, con motivo de mi jubilación, en el Aula Magna de la Facultad de Geografía e Historia de la Universidad Complutense de Madrid el 9 de octubre de 2007. 
Recibido/Received 2011-04-15

Aceptado/Accepted 2011-12-30

A dos grandes maestros de la sociología -Max Weber y Ernst Troeltsch-se les responsabiliza de consagrar ciertos términos que definen las distintas formas de agrupación de fieles: la iglesia, la secta, el culto y la denominación. ${ }^{2} \mathrm{~A}$ las dos primeras cabe remitirse de forma especial. La Iglesia se habría caracterizado por su afán de universalidad, el sentido compulsivo de la pertenencia, la fuerte organización jerárquica y la notable capacidad de adaptación a los asuntos seculares. Al término secta le otorga por lo general una acepción eminentemente peyorativa que, en puridad sociológica, no le corresponde. En muchas ocasiones se le considera intercambiable de la expresión herejía, aunque a la secta habría que identificarla con el grupo humano, mientras que a la herejía habría que considerarla como la opción filosófica que ese grupo adopta. ${ }^{3}$ A diferencia de la iglesia, la secta se caracteriza por la pertenencia voluntaria, una jerarquía más laxa que la de la iglesia, el alto nivel de exigencia de los fieles y su alejamiento de los asuntos mundanos.

Ello no obsta para que, en numerosas ocasiones lo que inicialmente ha sido una secta acaba por convertirse en iglesia a fin de ganar respetabilidad.

Uno de los temas, que viene preocupando muy especialmente a los historiadores en general y a los medievalistas en particular, es el de las formas de integración y exclusión que se dan en la sociedad. ${ }^{4}$ Dado el omnipresente papel del hecho religioso en el mundo medieval, la forma más importante de integración la facilitaría la Iglesia en su sentido de comunión. Como contrapartida, la forma mas abrupta de exclusión seria la excomunión

\section{IGLESIA Y MEDIEVO: A LA BÚSQUEDA DE UNA DEFINICIÓN INTEGRADORA}

El modelo sociológico por excelencia de iglesia lo da la Iglesia católica, especialmente la del Medievo y desde la perspectiva romanista.

${ }^{2}$ Para estas categorías vid Johnson, H. M. 1968: «Grupos religiosos», Sociología de la religión y de la moral, T. Parsons (ed.): 147 y ss. Buenos Aires: Paidos.

${ }^{3}$ Haeretici diversarum sectarum, dirá, en el II Concilio de Lyon de 1274 el general de los dominicos Humberto de Romans. Mansi, G. D. 1780. Sacrorum conciliorum nova et amplissima Collectio 2: 109-110. Venetiis: Apud Antonium Zatta.

${ }^{4}$ El título del presente artículo debe, así, mucho al de Asenjo, M. 2008 «Integración y exclusión. Vicios y pecados en la convivencia urbana», Pecar en la Edad Media, Carrasco A. I. y Rábade M. P. (coords.): 185-208. Madrid: Sílex Universidad. 
Según Johann Auer, en la consagración de este vocablo han contado diversos elementos. Los elementos proto-mesohebraicos se dan en tanto los cristianos se considerarán «hijos de Abrahán» o «nuevo Israel» y los elementos meso-tardohebraicos en tanto, a través de la Septuaginta, la iglesia adquirirá un sentido de comunidad de culto similar al existente en la sinagoga. Los elementos griegos derivan del propio vocablo «ekklesia» por el que se conocía en la polis griega a la asamblea popular. Los elementos neotestamentarios: integran hasta ciento catorce citas, aunque en los Evangelios canónicos sólo se la encontramos en dos ocasiones -en San Mateo- especialmente en el conocido y debatido pasaje de «tu eres Pedro y sobre esta piedra edificaré mi iglesia» (Mt. 16, 18) considerado desde la ortodoxia católica como autentica piedra angular. Por último, los elementos romanos dimanan del hecho de definirse la Iglesia de acuerdo con las ideas de orden y derecho (ordo et lex) y de conciencia de estado (civitas) que reforzarán en la Iglesia ese sentido jerárquico y organizativo. ${ }^{5}$ Dicho con otras palabras: el cristianismo primitivo, fue tomando cuerpo institucional y adquiriendo una progresiva vocación de universalidad a través de su contacto con tres realidades que fue capaz de ensamblar: la matriz palestina, la cultura helénica y la trabazón administrativa romana.

Bien es sabido como las «variaciones del concepto de Iglesia en su historia» ${ }^{6}$ se han prestado a diversas especulaciones a las que el Medievo no fue ni mucho menos ajeno. Así, la de la dialéctica entre iglesias particulares e Iglesia universal que se encuadra en el debate entre estructuración «federal»versus estructuración orgánico-mística. ${ }^{7}$ Así, la dualidad planteada por algunas tendencias, anatematizadas como heréticas, de Ecclesia sanctorum frente a Ecclesia malignantium. Una de sus variantes concebiría la Iglesia como universitas praedestinatorum de la que hablaría, entre otros, el reformador inglés Juan Wyclef. ${ }^{8}$ Estaríamos así ante una exacerbación de la esencia de la Iglesia en el «ordenamiento invisible de lo santo» (communio sanctorum). ${ }^{9}$ Desde el lado católico tomaría cuerpo una definición de Iglesia que, por la vía de los catecismos de inspiración tridentina, ha llegado casi hasta nuestros días: «congregación de los fieles cristianos [fuera de la cual no hay salvación, según la conocida y glosada máxima] cuya cabeza es el papa». ${ }^{10} \mathrm{~A}$ través de un uso progresivamente restrictivo del término,

\footnotetext{
${ }^{5}$ Auer, J. 1960. La Iglesia Curso de Teología dogmática: 46-70. Barcelona: Herder.

${ }^{6}$ Küng, H. 1970: La Iglesia: 17 Barcelona: Herder.

${ }^{7}$ Cf. Lubac, H. de. 1974. Las iglesias particulares en la iglesia universal: 52-53. Salamanca: Ediciones Sígueme.

${ }^{8}$ Tema tratado en Mitre, E. 2008. «Los pecados desde la herejía: la moral del otro en la Edad Media», Pecar en la Edad Media: 281-295. Madrid: Sílex Universidad.

${ }^{9}$ Auer J. 1960: 117.

${ }^{10}$ Respuesta a la pregunta ¿Quién es la Iglesia?, recogida en 1944. Catecismo de la doctrina cristiana escrito por el P. Gaspar Astete de la Compañía de Jesús. Dispuesto en orden cíclico: 22. (Decimaoctava edición). Valladolid.
} 
por iglesia se llegaría a entender exclusivamente la jerarquía eclesiástica. ${ }^{11}$ Una acepción que constituye un equívoco en el que hay responsabilidades compartidas; pero un equívoco que, en términos prácticamente absolutos, ha acabado por ser, socialmente, asumido.

Una definición más acorde con las orientaciones promovidas desde el concilio Vaticano II es la del medievalista (importante este dato para lo que concierne a este artículo) José Sánchez Herrero, que habla de «Comunidad de los hombres que, llamados por Cristo, creen en El y le siguen. Esta comunidad, a lo largo de los siglos, se ha dotado de diferentes miembros, instituciones y funciones, llegando a constituirse en los siglos medievales en un verdadero Estado similar a los otros estados feudales de la época y se extendió desde Oriente al Occidente europeo». ${ }^{12}$ Es obvio que el campo hoy en día abarcado por la Historia de la Iglesia (medieval en el caso que aquí nos interesa) cubre un amplio espectro tiempo atrás descuidado por visiones que resultaban escoradas hacia lo apologético. ${ }^{13}$ Esa áspera dualidad de la que antes hemos hablado puede ser así superada mediante una cierta complementariedad: la que abarca «en una sola mirada la Iglesia como cuerpo de Cristo y la Iglesia como sociedad de forma humana, la Iglesia como familia de Dios y la Iglesia como comunidad temporal». ${ }^{14}$

Desde los tempranos tiempos patrísticos (caso de Cipriano de Cartago en el siglo III) la Iglesia se identifica con la concordia, la unanimidad, la universalidad: «no pueden permanecer en comunión con Dios los que no quisieron permanecer unánimes en la Iglesia de Dios». ${ }^{15}$

${ }^{11}$ Se ha especulado con una tendencia, a partir de los Papas del siglo XI como Gregorio VII y Urbano II, a identificar Ecclesia con estamento eclesiástico, mientras que la sociedad cristiana pasaría progresivamente a ser definida como Christianitas o populus christianus. Congar, Iv.-M. 1976. Eclesiología. Desde San Agustín hasta nuestros días: 64-65. Madrid: Biblioteca de Autores Cristianos.

${ }^{12}$ Sánchez Herrero, J. 2005. Historia de la Iglesia II Edad Media: XIX. Colección Sapientia Fidei. Serie de Manuales de Teología. Madrid: Biblioteca de Autores Cristianos. Se actualiza en esta visión de la Historia de la Iglesia, la muy clásica, promovida por esta misma editorial en los años cincuentasesenta, bajo la coordinación de B. Llorca, R. García Villoslada y Montalbán. Hace también bastantes años, J. Lortz decía que la Iglesia «es ante todo, un organismo. Su historia es, por tanto, una». Al componerse, sin embargo, de cuerpo y alma, se realiza en hombres mortales y su vida es múltiple: fundante, interior y exterior. Lortz, J. 1962. Historia de la Iglesia desde la perspectiva de la historia de las ideas. Exposición e interpretación histórica del pasado cristiano: 22. Madrid: Ediciones Guadarrama.

${ }^{13}$ Vid la panorámica recogida por Sanz Sancho, I. 1998. «Para el estudio de la Iglesia medieval castellana», Estudios eclesiásticos 284: 63-87, especialmente pp. 62-66. Significativo, por ejemplo, el título de la síntesis de Chelini, J. 1968. Histoire religieuse de l'Occident medieval. París: Armand Colin. Y llamativo es, también, el título del artículo de Alberigo, G. 1970. «¿Nuevas fronteras en la Historia de la Iglesia?», Concilium: 57: 66-85.

${ }^{14}$ Birou, A. 1964. Sociología y religión: 91. Madrid: Instituto de Estudios Políticos.

${ }^{15}$ Cipriano. 1991: La unidad de la Iglesia: 88. Edición de Falla, C. y Pascual Torro, J. Madrid: Ciudad Nueva. 
El concepto de iglesia ha resultado así inseparable del de comunión que tiene un doble significado. Por un lado sacramental, identificado con el sacrifico eucarístico materializado en la transubstanciación. Una expresión que acabará imponiéndose frente al griego metabole, vertido al latín como conversio $^{16}$ y que se proclamará solemnemente en el IV concilio de Letrán en $1215 .{ }^{17}$ Por otro, el término latino communio (derivado del griego Koinomia) tiene el significado de compañerismo, participación o solidaridad en las liturgias en dos ejes: el horizontal, entre los distintos miembros de la Iglesia, y el vertical, a través del Espíritu en Cristo hasta el Padre. ${ }^{18}$

Estamos hablando, lógicamente, de un ideal que topará con numerosos inconvenientes. Entre los de más peso, la labor de zapa ejercida por una suerte de tríada maldita constituida por apostasía/cisma/herejía presentes hasta el momento actual en la legislación canónica. ${ }^{19}$ Implican realidades distintas pero acaban por adquirir una asociación pleonástica vistas desde el lado de la ortodoxia o recta opinión. ${ }^{20}$

De entre las medidas que desde ésta se tomen para atajar tales males, hay una especialmente destacada: la excommunicatio como ruptura de la communio, de la participación en las liturgias y en los beneficios espirituales a los que el cristiano se había hecho acreedor. Relacionada en principio con la penitencia no es exactamente lo mismo ya que a lo puramente teológico, moral y pastoral se añade una fuerte carga jurídica. ${ }^{21}$ Un paso importante para convertir a la excomunión en un arma algo más que espiritual y que, con otros nombres, encontramos en todo tipo de sociedad. Una vez creado un orden jurídico se ponen en juego instrumentos para defenderse de quienes quieren socavar el orden establecido. $^{22}$

${ }^{16}$ Citado en Bouyer, L. 1977. «Transubstanciación», Diccionario de Teología: 631. Barcelona: Herder.

${ }^{17}$ «Decretos del IV Concilio de Letrán»1. De la fe católica. Recogido en Foreville, R. 1972. Lateranense IV: 156. Vitoria: ESET.

${ }^{18}$ O’Donell, C. y Pie-Ninot, S. 2001: «Comunión/Koinomia», Diccionario de Eclesiología: 192. Madrid: Ediciones San Pablo.

${ }^{19}$ Estas tres categorías figuran entre los «Delitos contra la religión y la unidad de la Iglesia» en el actual 1983. Código de Derecho Canónico: 601 Madrid: Conferencia Episcopal Española.

${ }^{20}$ Vid. Mitre, E. 2005.: «Herejías y sectas; herejías y cismas: la fluctuante tipología del Occidente medieval», en Iglesia de la Historia, Iglesia de la fe: 249-265. Homenaje a Juan María Laboa Gallego. Rivas Rebaque F. y Sanz de Diego, R. M (editores). Madrid: Universidad Pontificia de Comillas.

${ }^{21}$ García y García, A. 1967. Historia del derecho canónico I. El primer milenio: 142-143. Salamanca: Instituto de Historia de la Teología Española.

${ }^{22}$ Mörsdorf, K. 1979. «Excomunión», Conceptos fundamentales de la teología tomo I. Fries, H. (director): 536-537. Madrid: Ediciones Cristiandad. 
UNA FILOSOFÍA Y UNA PROTOHISTORIA PARA LA EXCOMUNIÓN MEDIEVAL

Entre los elementos constitutivos podríamos reconocer los siguientes: Elementos eclesiales: escriturarios, patrísticos y protoconciliares, la proyección de elementos jurídicos romanos.

\section{a. Elementos eclesiales (escriturarios, patrísticos y protoconciliares) ${ }^{23}$}

En el Antiguo Testamento se han detectado diversos textos del tipo «imprecación legislativa». ${ }^{24}$ Así las maldiciones contra quienes desobedezcan los preceptos divinos, entre ellos la prohibición de la idolatría (Lev. 26, 14). Así, las súplicas al Señor para que no mire con dureza a su pueblo, ni su impiedad, ni su pecado (Dt. 9, 27). ${ }^{25}$ La palabra jerem (lo que está prohibido) se usa en la Septuaginta como anatema contra la idolatría, la unión con mujeres extranjeras o los ataques contra la función ministerial. ${ }^{26}$

Se ha recordado que para Graciano, padre del Derecho Canónico en los años centrales del siglo XII, y a su estela los decretalistas, la expulsión del Paraíso supuso una primera excomunión. ${ }^{27}$ Más prudente sería aplazar los lejanos orígenes de ésta situándolos en dos pasajes del Evangelio de San Mateo. Uno, la recomendación de corregir al hermano pecador dándole tres oportunidades, «pero, si ni a la iglesia oyere, tenle por gentil y publicano» (Mt. 18, 15-17). El otro estaría en esos poderes de atar y desatar otorgados al primado petrino (Mt. 16, 17-19). En San Pablo se daría también un importante aporte: «huye del hombre herético después de se le haya reconvenido una y dos veces» (Tit. 3,10 ).

A principios del siglo III, Tertuliano encomienda a la asamblea de fieles promulgar «exhortaciones, castigos y censuras en nombre de Dios» llegándose in-

\footnotetext{
${ }^{23}$ Panorámicas sobre este tema y para estos tiempos en Gaudemet, J. 1949. «Les formes anciennes de l'excommunication», Revue des Sciences Religieuses 23: 64-77. Bernhard, J. 1965. «Excommunication et pénitence-sacrement aux deux premiers siècles de 1'Eglise. Contribution canonique», Revue de Droit Canonique 15: 265-281, 318-330. 1966. 16: 41-70. Vogel, C. 1975. «Penitencia y excomunión en la Iglesia Antigua y en la Alta Edad Media», Concilium 107: 9-21.

${ }^{24}$ Tuya, M. de y Salguero, J. Madrid 1967.Introducción a la Biblia I. Inspiración bíblica. Canon. Texto. Versiones: 291. Madrid: Editorial Católica. Biblioteca de Autores Cristianos

${ }^{25}$ Mörsdorf, K. 1979: 537.

${ }^{26}$ Bach, D. 1993. «Anatema», Diccionario enciclopédico de la Biblia: 70-71. Barcelona: Herder.

${ }^{27}$ Marzoa, A. 1985. La censura de excomunión, Estudio de su naturaleza jurídica. Ss. XIII-XV: 73 Pamplona: EUNSA.
} 
cluso a «apartar de la comunión de oración, de la reunión y de toda ceremonia sagrada» a quien hubiera cometido un grave delito. ${ }^{28}$

Los concilios - generales o locales- como expresión de la voluntad de la (s) comunidad (es) cristiana (s) en sus primeros siglos promulgarán importantes disposiciones / orientaciones en esta dirección.

Así, el Concilio de Elvira (c. 295-c. 314) habla de abstineantur a communion, de forma temporal, para quienes incurriesen en determinadas infracciones de orden moral. ${ }^{29}$ En el Concilio de Ancira, celebrado en 315 en el Asia Menor, recordando la pena de exclusión de por vida a las mujeres que «fornicaron y mataron sus partos», suaviza esta sanción, imponiendo una penitencia de diez años. ${ }^{30}$

De mayor proyección por su consideración de primero de naturaleza ecuménica, el Concilio de Nicea (325) aparte de condenar el arrianismo, pronunciará una serie de medidas disciplinarias. Entre ellas, la prohibición a los obispos de recibir a clérigos y laicos que hubieran sido excomulgados por un obispo vecino: «que los rechazados por unos (obispos) no sean admitidos por otros (obispos)»». ${ }^{31}$ Una medida que se reiterará en concilios de entidad regional como el de Zaragoza de 380 en donde se amenaza con excomunión a los obispos que incumplieran esta norma. ${ }^{32}$ En el concilio provincial de Cartago de 390 la expresión excomunión aparece para referirse al castigo a un pecador contumaz. ${ }^{33}$

En esta línea, se ha advertido, profundizarán autores de la talla de San Agustín o San Ambrosio. ${ }^{34} \mathrm{El}$ ejemplo de este último en relación con el emperador Teodosio tendrá un profundo significado: la prohibición de entrar en la basílica de Milán hasta que no se arrepintiera públicamente de la masacre causada por sus soldados a la población de Tesalónica. Un obispo se entromete por primera vez en la vida pública como defensor de la fe y de la moral. ${ }^{35}$ Penitencia pública y alejamiento de la comunión acabarán por complementarse.

\footnotetext{
${ }^{28} 1997$ Tertuliano: Apologético: 148-149. Andino, J. (ed.). Madrid: Biblioteca de Patrística.

${ }^{29}$ 1963. Concilios visigóticos e hispanorramanos: 6 y ss. (Ed. Vives, J, Martínez Diez, G. y Marín, T. (eds): Madrid: Instituto Enrique Flórez, CSIC.

30 1859. «Concilio de Ancira», Colección de cánones y de todos los concilios de la Iglesia de España y de América, vol 1: 40. (Tejada y Ramiro, J. editor) Madrid: Imprenta de D. Pedro Montero.

${ }^{31}$ Can. 5 de «Cánones del concilio de Nicea», en Ortiz de Urbina, I. 1969, Nicea y Constantinopla: 263. Vitoria: ESET.

${ }^{32}$ Can. 5 de «Concilio de Zaragoza I», 1963. Concilios visigóticos: 17.

${ }^{33}$ Mörsdorf, K. 1979: 539.

${ }^{34}$ Respectivamente en De correptione et gratia, 14, 31. en donde habla del papel benéfico de la corrección fraterna para que los hombres vuelvan al buen camino; y en De Officciis ministrorum 2, 27, imitación de la obra homónima de Cicerón.

${ }^{35} \mathrm{El}$ derecho de un obispo a intervenir y a castigar se ejerce antes de ser definido formalmente. Paul, J. 2003. Historia intelectual del Occidente medieval: 102. Madrid: Cátedra.
} 


\section{b. La proyección de elementos jurídicos romanos}

La excomunión recibirá también una fuerte inspiración (o equiparación incluso) a ese status legal de infamia que en Roma descalificaba a las personas faltas de honor y de respetabilidad dado su comportamiento o el ejercicio de determinadas profesiones. ${ }^{36}$ Un elemento más en la connivencia entre los poderes civil y eclesiástico al fijar reglas y consecuencias de la excomunión

Así, las leyes imperiales del siglo $\mathrm{V}$ prohibirían a donatistas y maniqueos hacer compras, contratos, regalos, etc... tratándoseles de traidores.

El Codex Theodosianus (437) reforzó las medidas contra los heréticos, merecedores por excelencia de la excomunión (pellere, expellere, segregare, excludere), que suponen el perfecto complemento jurídico de la excomunión

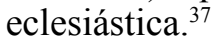

En el Occidente, la pena de excomunión se haría extensiva, en los primeros siglos del Medievo, a quienes osaran tener contacto con los que ya hubieran incurrido en ella. Lo harán, por ejemplo, el I y II concilios provinciales bracarenses del 561 y $572 .{ }^{38}$ Y lo hará mas tarde Carlomagno en una disposición civil, pero con honda significación espiritual también: La $A d$ monitio Generalis (c. 789), en donde, igualmente, se condena con la excomunión a «quien tuviera la audacia de comunicarse con un excomulgado». ${ }^{39}$ Los tiempos carolingios conocerían, a su vez, la promulgación de medidas contra quienes usurpasen bienes de la Iglesia o ejerciesen el pillaje contra los campesinos. ${ }^{40}$ Sería la prehistoria de un importante giro en la historia de Europa.

\footnotetext{
${ }^{36}$ Para el caso, por ejemplo, de la usura en donde se conjugan como penas la excomunión y la infamia canónica. Destacado por Brundage, J. A. 1995. Medieval Canon Law: 77. London: Longman.

${ }^{37}$ Escribano, M. V. 2007. «Formas de violencia contra heréticos en Codex Theodosianus XVI, 5 (De haereticis)», en Bravo, G. y González Salinero. R (eds.), Formas y usos de la violencia en el mundo romano. (Actas del IV Coloquio de la Asociación interdisciplinar de Estudios Romanos): 77. Madrid: Signifer Libros.

${ }^{38}$ Can XV del «Concilio de Braga I», 1963. Concilios visigóticos: 74 y en Cánones XXXVII y LXXXIV del «Concilio de Braga II», ibídem: 106.

39 «Admonitio generalis», cap. 36, recogido por Belperrie du Bayac, J. 1977. Carlomagno, 287. Barcelona; Ayma.

${ }^{40}$ Caso del tardocarolingio concilio de Trosly (909) presidido por el arzobispo Hervé de Reims. Suele tratarse en estos años de excomuniones parciales en las que el penado se reconcilia mediante algún tipo de transacción. Barthelemy, D. 2006. Caballeros y milagros. Violencia y sacralidad en la sociedad feudal: 27-30. Univesitat de Valencia-Universidad de Granada 2006.
} 


\section{c. El recodo del Año Mil}

Estamos, ante lo que se ha considerado como una «revolución», no ya por unos terrores generalizados, sobre los que se sigue aún especulando, al calor del reciente cumplimiento del tercer milenario del nacimiento de Cristo ${ }^{41}$ Por lo que aquí concierne, lo innovador de esta fecha se refiere al nacimiento de una institución, las Asambleas de paz y Tregua de Dios ${ }^{42}$ que darían un nuevo impulso a la excomunión como sanción religiosa y algo más que religiosa.

La versión, tradicionalmente admitida, hace datar esta institución en el Concilio de Charroux de 989. Sería impulsado por el episcopado del mediodía de Francia, que tomaría el relevo de una desaparecida autoridad real, a fin de, con su peso moral, imponer un cierto orden frente a la anarquía feudal desatada. ${ }^{43}$ Más que erradicar la violencia reinante se trataría de someterla a cierto control. Para ello, se prohibirá combatir en determinadas fechas y períodos del calendario litúrgico y atacar a la multitudo inermis vulgi, es decir, a los pauperes, id est, agricultores. La pena de excomunión con la que se amenaza a los infractores supondría una suerte de venganza divina. ${ }^{44}$

En la primitiva Cataluña, el Abad-Obispo Oliba sería el gran impulsor del movimiento. En el Sínodo de Toulouges o Elna de 1027, primero de los tres que presidirá, se extenderán socialmente las penas: hacia quienes atenten contra los bienes de la Iglesia pero también contra quienes cohabiten con persona hasta sexto grado de parentesco. Se da un plazo de tres meses para que el pecador se arrepienta y, en caso contrario, excommunicatus permaneat, no recibiendo sepultura cristiana ni oraciones de clérigos ni fieles. ${ }^{45}$

${ }^{41}$ Evitamos la remisión a los numerosos títulos en torno a los «terrores del Año Mil» y nos conformamos con recoger las recientes referencias de J. Flori que opone «falsos terrores» a «auténticas tensiones» en torno a esta fecha. Flori, J. 2010. El Islam y el fin de los tiempos. La interpretación profética de las invasiones musulmanas en la Cristiandad medieval: 163-172. Madrid: Ediciones Akal.

${ }^{42}$ Entre otros estudios sobre el tema vid. Head T. y Landes, R. (Eds.) 1992. The Peace of God. Social Violence and Religious Response in France around the Year 1000. London, Ithaca-New York: Cornell University. Barthelemy, D. 1999. L'An Mil et la paix de Dieu. Paris: Fayard. Interesante la nota crítica de Pascua, E. 1995. «Violencia, escatología y cambio social. La polémica en torno al movimiento de Paz de Dios», Hispania: LV/2 190: 727-737.

${ }^{43}$ Visión cuestionada hoy en día por algunos autores como Barthelemy, D. 2006: 73.

${ }^{44}$ Duby, G. 1973. «Les laïcs et la paix de Dieu», Hommes et structures du Moyen Age: 227-252. Paris: Flammarion.

${ }^{45}$ «Concilio de Elna», también llamado Tulujense, año 1027. En Tejada y Ramiro, J. 18491855. Colección de cánones de todos los concilios de la Iglesia de España y América: vol. III: 83. Madrid. Sobre el personaje, son clásicos los dos libros de Albareda, A. 1931. L'abat Oliba, fundador de Montserrat. Assaig biogràfic. Monestir de Montserrat. Abadal, R. d'. 1948. L'Abat Oliba, bisbe de Vic y la seva època. Barcelona: Salva. Hay una reedición. 2003. Pamplona: Urgoiti Editores S.L. Interesante también el reciente trabajo de Ruiz Doménech, J. E. 2004. «El abad Oliba: un hombre de paz en tiempos de guerra», en Ante el Milenario del reinado de Sancho el Mayor. Un rey navarro para España y Europa (XXX Semana de Estudios Medievales. Estella 2003): 173-196. Pamplona: 
Por los mismos años y en el interior de la España cristiana, el Concilio de Coyanza (celebrado entre 1050 y 1055) aplicaría al Reino de León ciertos principios de la paz de Dios: en razón de sus comportamientos serían severamente castigados adúlteros, incestuosos, ladrones, agentes de maleficio: separentur ab Ecclesia et a communione ${ }^{46}$ Pero también serían sancionados quienes «desprecien la verdad y la justicia del rey». Se ha jugado, en este caso, con una influencia de los concilios toledanos celebrados entre el 400 y el 700 que, con escaso éxito, habían elaborado toda una serie de medidas para proteger las personas de los reyes. ${ }^{47}$

Burkardo, obispo de Worms que vivió por los años en que tomaba cuerpo la institución de la paz y tregua de Dios, dedicaba el libro décimo de su Decreto al tema De excommunicatione, desarrollado en 78 capítulos referidos entre otros temas a hurtos, rapiñas, delincuentes, sacrílegos..., clérigos que huyen de su iglesia, siervos que marchan del dominio propio. Asimismo se extiende la excomunión a quienes tuvieran contacto con excomulgados condenándoseles a cuarenta días a pan y agua cum septem sequentibus annis poenitere..$^{48}$

El terreno de la praxis excomunicatoria aplicada a diversos campos e infracciones quedaba así suficientemente abonado al entrar en la plenitud del Medievo.

\section{GREGORIANISMO, LATERANISMO Y CANONÍSTICA}

El pontificado, máxima expresión de la jerarquía eclesiástica será quien más llamativamente explote el recurso a la excomunión. Será una práctica consustancial a la regeneración impulsada -aunque no en exclusiva- por los papas desde mediados del siglo XI. La figura de Hildebrando, papa Gregorio VII (10731085) ha pasado a dar nombre a este movimiento que empieza por una lucha a favor de la libertas Ecclesiae frente a la tutela de los poderes temporales y que derivará en una política sistematizada por los papas y sus asesores para asignar a la iglesia de Roma la plenitudo potestatis o soberanía sobre los asuntos tanto espirituales como temporales. ${ }^{49}$ En la defensa de esos principios, la excomunión

\footnotetext{
Departamento de Educación. Gobierno de Navarra. Sobre el movimiento de paz y tregua en territorio catalán vid. Gonzalvo, G. 1994. Les constitucions de pau i treva de Catalunya (segles XI-XIII). Barcelona: Departament de Justícia. Generalitat de Catalunya.

${ }^{46}$ «Concilio de Coyanza 1088» tit. IV, Tejada y Ramiro. J. 1859: vol. III, 97.

${ }^{47}$ Cf. el excelente trabajo de García Gallo, A. 1950-1951: «El Concilio de Coyanza», en Anuario de Historia del Derecho Español 20: 275-633.

${ }^{48}$ Burchardus Wormatiensis, Decretum, Patrologia Latina CXL, cols 857-969.

${ }^{49}$ Para este proceso sigue siendo de gran utilidad la excelente síntesis de Pacaut, M. 1957. La théocratie. L'Eglise et le pouvoir au Moyen Age. París: Aubier. Desde entonces han sido numerosas las publicaciones sobre el tema. Entre ellas, 2006. La reforma gregoriana y su proyección en la cristiandad occidental. Siglos XI-XII. Actas de la XXXII Semana de Estudios Medievales (Estella 2005). Pamplona: Gobierno de Navarra, Institución Príncipe de Viana.
} 
será un arma especialmente utilizada frente a las distintas instancias, incluidas las mas encumbradas. Al actuar la misma potestad de jurisdicción (forum Ecclesiae) sobre dos campos (forum poenitentiale y forum iudiciale) la excomunión experimentó un giro: de tener un sentido religioso para castigar graves pecados, adquirirá también el sentido de censura con fines temporales. En lenguaje mas llano, la incidencia penitencial-social de la excomunión se doblará en otra también política. ${ }^{50}$

\section{a. La escenificación conciliar y su proyección inquisitorial}

El gregorianismo y el postgregorianismo, lato sensu, (hasta entrado el siglo XIII) relevará a Oriente (Iglesia de los Siete concilios definidores de las grandes verdades de fe) en la iniciativa de celebrar grandes asambleas conciliares. La tradición eclesiástica ha otorgado la consideración de ecuménicos a cuatro grandes concilios celebrados en la basílica de San Juan de Letrán en los que la figura de la excomunión cobrará un decisivo impulso.

Letrán I (1123) reiterará las disposiciones de Nicea prohibiendo solemnemente a «obispos, abades y clérigos recibir en comunión a aquellos que han sido excomulgados por su propio obispo». ${ }^{51}$

Letrán II (1139) a través del canon Si quis suadente, impulsará la excomunión latae sententiae por la que la condena tiene efectividad desde el momento de incurrir en un grave crimen sin que sea imprescindible una sentencia efectiva. Se extiende, asimismo, la excomunión a quienes colaboren con excomulgados. ${ }^{52}$

El Letrán III, convocado por el papa Alejandro III (1179) reafirmará la aplicación latae sententiae pero también exigirá que los obispos no pronuncien sentencia de suspensión o excomunión «sin amonestación previa a menos que la falta sea de naturaleza que por si misma entrañe excomunión». ${ }^{53}$

Hablar del IV Concilio de Letrán (1215) es hablar, sobre todo de su promotor, el papa Inocencio III (1198-1216). La asociación entre hereje y merecedor de excomunión avanza un grado más con este pontífice. Al hereje se unirá en consideración reprobatoria el fautor de herejes, una figura no del todo nueva pero que adquiere unos perfiles más acusados. Será aquel que no sólo trata con

\footnotetext{
${ }^{50}$ Mörsdorf, K. 1979: 540-541.

${ }^{51}$ «Decretos del Primer Concilio de Letrán» can. 2, en Foreville. R 1972: 225.

${ }^{52}$ Vodola, E. 1986. Excommunication in the Middle Age: 28-29 y 34. Berkeley-Los Angeles: University of California Press. Frente a la figura de la latae sententiae se erigirá la de ferendae sententiae, en la que la excomunión solo es operativa cuando se pronuncia la autoridad competente.

${ }^{53}$ «Decretos del III Concilio de Letrán», decr. 6, en Foreville, R.: Lateranense I, II y III, p. 268-269.
} 
herejes (merecedor ya de por si de las máximas sanciones) sino que les oculta o da apoyo directo. «Nos excomulgamos a quienes prestan crédito a los herejes, los reciben, los defienden o los ayudan... (y) todo aquel que, excomulgado por tales faltas descuidara satisfacer dentro del plazo de un año será ipso facto declarado infame».${ }^{54}$ En esa línea, algún posterior manual de inquisidores (de finales del siglo XIV revisado en el siglo XVI) insistiría en esta figura hablando de acogedores de herejes, anfitriones de herejes o bienhechores de herejes que serían «excomulgados ipso facto y declarados suspectos de herejía». ${ }^{55}$

Los Concilios Lugdunenses (Lyon I de 1245 y Lyon II de 1274) recalcarían esta política con alguna escenificación especialmente dramática.

\section{b. La sistematización canónica y su influencia en el derecho civil}

El derecho eclesiástico tuvo a mediados del siglo XII en el monje camaldulense Graciano, con su Decreto (Concordia discordantium canonum) el reconciliador de las diferentes tradiciones canónicas y prescripciones que conducirán a un «sistema unificado e intelectualmente consistente». ${ }^{56}$ La idea romana de infamia, que se había transmitido a lo largo de los siglos, cobrará un fuerte impulso en el derecho eclesiástico. ${ }^{57}$ En 1199, el papa Inocencio III en la decretal Vergentis in senium, equipararía herejía y crimen de lesa majestad típica del Derecho romano ${ }^{58}$.

Alejandro III e Inocencio III serían (al igual que buena parte de sus sucesores a lo largo del siglo XIII) expertos conocedores de un derecho canónico, puesto al servicio de los intereses de la plenitudo potestatis papal. Sistematizaciones legales unidas a esas escenificaciones conciliares potenciarían una «doctrina científicamente elaborada» de la excomunión. ${ }^{59}$

El Maestro general de los dominicos, canonista y autor de un Directorio para uso de inquisidores Raimundo de Peñafort ${ }^{60}$ diría que «Excommunicatio est a

\footnotetext{
${ }^{54}$ «Decretos del IV Concilio de Letrán», can. 3 en Foreville, R. 1972: 160.

${ }^{55}$ Eimeric, Nicolau y Peña, Francisco.1983. Manual de inquisidores, Sala Molins, L. y Martín, F. (eds.): 100-102. Barcelona: Muchnik.

${ }^{56}$ Brundage, J. A. 1995: 47.

${ }^{57}$ Vodola, E. 1986. Para esta cuestión en la canonística europea vid. Landau. P. 1966. Die Entstehung des kanonischen Infamiebegriffs von Gratian bis zur Glossa ordinaria. Colonia: H. Böhlaus.

${ }^{58}$ Lambert, M. D. 1986. La herejía medieval. Movimientos populares de los bogomilos a los husitas: 116. Madrid: Taurus. Esta decretal sería un anticipo de esa declaración de infamia fijada solemnemente en el IV concilio de Letrán.

${ }^{59}$ Marzoa, A. 1985: 15.

${ }^{60}$ Hay un capítulo dedicado al tema del personaje y la Inquisición en la ya venerable semblanza de Valls Taberner, F. 1936. San Ramón de Penyafort: 104-116. Barcelona. Hay una reedición, 1979. San Ramón de Penyafort. Barcelona: Labor.
} 
qualibet licita comuniones vel legitimo actu separatio». ${ }^{61} \mathrm{Y}$ otro dominico, el inevitable Tomás de Aquino popularizaría la diferencia entre excomunión mayor que suponía la exclusión de la «communio fidelium» y de la recepción de los sacramentos, y la excomunión menor que suponía la mera «separatio tantum a partitione sacramentorum». ${ }^{62}$

El código de Las Siete Partidas de Alfonso X el Sabio expresa en numerosos pasajes lo que fue la influencia del derecho canónico en la legislación civil. De manera muy especial lo veremos en las leyes en las que se nos describe tanto la excomunión como su casuística. La define en general como «sentencia que estraña e aparta al ome contra quien es dada alas vezes de los sacramentos de Santa Eglesia, e a las vegadas de las compañas de los leales Christianos». Recoge la distinción del Aquinate en lo que se refiere a excomunión mayor y excomunión menor y sitúa a un nivel menor de excomunión el «entredicho y suspensión».

El primero (una sanción con carácter local o territorial que puede abarcar incluso un reino entero) se define como castigo por los «yerros que fazen sus parochianos e non queren fazer emienda dellos»; mientras que la suspensión supone dejar en desuso un oficio a las «personas de los homes por los yerros que fazen cada uno dellos». ${ }^{63}$ Se reconocen hasta diez y seis maneras de incurrir en excomunión: desde la caída en herejía, pasando por negar el reconocimiento de la iglesia de Roma como «cabeça de la fe» hasta ir contra las franquezas y libertades de la Iglesia». ${ }^{64} \mathrm{La}$ facultad de excomulgar corresponde a «obispos e otros perlados menores» en el territorio de su jurisdicción. A los primeros y no a los segundos se les reserva la capacidad de excomunión solemne. ${ }^{65}$

\section{Algunos modelos PRÁCticos}

Esa amplia capacidad de castigar muy diversos pecados con la exclusión de la comunidad convertirían en turbulentas las relaciones entre el poder temporal y el espiritual a lo largo del Medievo. Pocos príncipes seculares se vieron libres,

\footnotetext{
${ }^{61}$ Raimundo de Peñafort, Summa de Poenitentia, cit. 1, III tit. 33 n 9, col. 746. Recogido en Marzoa, A. 1985: 82 .

${ }^{62}$ Santo Tomás de Aquino: «Supplementum» a la III pars de la Suma Teológica q. XXI, citado también en Marzoa, A. 1985: 36. El anatema no sería una excomunión especial sino otra forma de hablar de la excomunión mayor. ibídem: 130. El sínodo de Touluges entendía por anatema la pena en que se incurría cuando, después de un plazo de tres meses no se hacía caso de la excomunión recibida. Tejada y Ramiro. J. 1859: III: 83.

${ }^{63}$ Sobre las penas privativas de los clérigos, deposición, suspensión, privación de estipendios, exclusión de la comunión con los demás obispos y comunión peregrina vid. A. García y García, A. 1967: 264-265.

${ }^{64}$ Primera Partida Tit. IX, de ley I a ley XIII,

${ }^{65}$ Ibídem: ley XIII.
} 
si no de una excomunión efectiva, sí de una seria amenaza de sufrirla. Algunas excomuniones pontificias lanzadas contra monarcas -muy pagados también de su poder en materia espiritual- adquirirán, por el eco despertado y las consecuencias políticas anejas, una especial relevancia. Valga un puñado de ejemplos / modelos.

Estaría en primer lugar, el marcado por las excomuniones de papas contra emperadores, que serán harto frecuentes. La más llamativa vendrá del enfrentamiento entre Enrique IV y el Papa Gregorio VII, a propósito del conflicto de las investiduras. El Pontífice aplicaría a su oponente el pretendido derecho papal a «desligar del juramento de fidelidad (que los vasallos habían prestado) a un monarca inicuo»». ${ }^{66}$ Un gesto, que marcará un antes y un después en la historia del tema que nos atañe. Incluso -humillación del monarca en Canossa por medio en 1077- pesará como una losa en las relaciones Imperio-Iglesia a lo largo de la Historia. ${ }^{67}$

En segundo lugar estamos ante excomuniones derivadas del enfrentamiento entre jurisdicciones. La mas dramática vendría del choque entre el primado de la iglesia inglesa, Tomás Becket, y Enrique II Plantagenet, apoyado, no hay que olvidarlo, por un cierto número de prelados de la isla.$^{68}$ El fantasma de la excomunión estará varias veces presente. Lo estará en la pretensión real de limar (Constituciones de Clarendon de 1164) los privilegios de los tribunales eclesiásticos ingleses y de cercenar las posibilidades de excomulgar a vasallos directos y oficiales del rey, sin que las acusaciones contra ellos pasaran antes por los tribunales reales ${ }^{69}$ Lo estará en la excomunión lanzada contra varios obispos ingleses por Tomás a su retorno del exilio de Francia. Y lo estará sobre todo cuando, tras el asesinato del primado (1170), el Papa Alejandro III sancione a Enrique II con un impedimento ab ingressu Ecclesiae y someta a entredicho sus dominios en Francia. A la postre la crisis se solucionaría con el llamado Concordato de Avranches, de 21 de marzo 1171, por el que el Monarca se comprometía a ciertas obras expiatorias y a suavizar las disposiciones de Clarendon. ${ }^{70}$

Un tercer caso se da cuando el papa aplique la más grave sanción canónica a un monarca, de quien se reprueba su conducta familiar, aunque ello se mez-

${ }^{66}$ Dictatus Papae, art. 27 de los, recogido entre otros por Gallego Blanco, E. 1973. Relaciones entre la Iglesia y el Estado en la Edad Media: 185. Madrid: Revista de Occidente.

${ }^{67}$ Zimmerman, H. 1975. Der Canossagang von 1077. Wirkungen und Wirklichkeit. Wiesbaden: Franz Steiner Veerlag. Aun en 1873, en plena Kulturkampf, el canciller Bismarck afirmaría en el Reichstag: ¡Jamás volveremos a Canossa!

${ }^{68}$ Destacado en una biografía del arzobispo de Canterbury, menos complaciente con su personalidad de lo que ha sido frecuente. Barlow, F. 2010 Tomás Becket el santo político. Barcelona: Edhasa.

${ }^{69}$ «Constituciones de Clarendon. Cap. VII», en Stubbs, W. 1884. Selects Charters and other Illustrations of English Constitutional History: 137-140. Oxford: Clarendon Press.

${ }^{70}$ Foreville, R. 1972. Lateranense I, II y III: 157-159. 
cle muchas veces con factores políticos. Sería el caso de Alfonso IX de León, excomulgado en dos ocasiones a causa de dos matrimonios (con las infantas Teresa de Portugal y Berenguela de Castilla), viciados por la consanguinidad. La primera sanción lanzada por Celestino III se agravó algún tiempo con el entredicho a la totalidad del Reino, por negarse, en principio, los obispos de León, Astorga, Zamora y Salamanca a aceptar la decisión papal. Hasta 1204 no se regularizaría, definitivamente, la situación al plegarse el monarca a las exigencias de Inocencio III. ${ }^{71}$

El cuarto modelo lo facilita el monarca como fautor de herejes. Así, la excomunión será la amenaza con la que juegue el legado papal Arnaldo Amaury por la actitud del Rey de Aragón Pedro II. Aunque ortodoxo sincero (según la tradición Pedro el Católico por haber infeudado sus estados a la Santa Sede), había acudido en 1213 en ayuda de sus parientes filocátaros del mediodía de Francia. Con tan mala fortuna de perder la vida en el combate de Muret frente al ejercito cruzado de Simón de Montfort. ${ }^{72}$

Un caso especial, verdadero epítome de todas las taras que según la Iglesia descalificaban a un monarca, lo facilita el emperador alemán y rey de Sicilia Federico II. Figura fascinante donde las haya, declaró a los herejes enemigos del estado ${ }^{73}$ pero sus reiterados enfrentamientos con sucesivos pontífices crearían en ciertos sectores una especial mala prensa hacia su persona. A la excomunión lanzada por Gregorio IX en $1229,{ }^{74}$ sucedería otra de mayor trascendencia política y canónica: la lanzada, tras un solemne proceso en el Concilio de Lyon de 1241, convocado por Inocencio IV. El peculiar comportamiento del emperador frente al papado le declaraba sospechoso de herejía «tanto en su pensamiento como en sus actos». ${ }^{75}$

$\mathrm{Al}$ asimilar éstos a creencias erróneas se estaba sin duda incurriendo en una exageración. No así cuando se hablaba de las acciones (suficientemente comprobadas) del monarca contra la autoridad y los intereses de la Iglesia.

\footnotetext{
${ }^{71}$ Para el largo contencioso del que fue protagonistas este monarca vid. Tejada y Ramiro, J. 1859. «Concilio de Salamanca de 1192» III: 295.300. Sobre el tema de la consanguinidad como motivo para romper el vínculo matrimonial vid. Pérez de Tudela. M. I. 2008. «El concepto de pecado como arma de control político: el matrimonio de Alfonso IX de León y Berenguela de Castilla», Pecar en la Edad Media: 81-96. Madrid: Sílex. Universidad.

${ }^{72}$ Para esta dramática historia vid. la excelente monografía, de Alvira, M. 2002. 12 de septiembre de 1213 El jueves de Muret. Barcelona: PPU. Promociones y Publicaciones Universitarias.

${ }^{73}$ Tal y como se recogerá en un edicto incluido en el Liber augustalis. Cf. Kantorowicz, E. 1987. L'empereur Fréderic II: 243. Paris: Quarto Gallimard (edición original alemana de 1936). Se trata, sin duda, de una de las más impactantes biografías sobre un monarca europeo del Medievo.

${ }^{74}$ Wolter, W. y Holstein, W. 1979. Historia de los concilios ecuménicos .Lyon I y Lyon II: 23. Vitoria: Editorial ESET.

${ }^{75}$ «Bula «Ad Apostolicae dignitatis», ibídem: 312.
} 
¿CRÍtica y desGaste de Un PROCEDIMIENTO?

El paso de los siglos XIII al XIV supone un importante giro en las relaciones estado (Felipe IV de Francia)-Iglesia (Papa Bonifacio VIII). Tras borrascosas vicisitudes, la amenaza de excomunión contra el francés fue respondida por éste con la humillación (intento de secuestro incluso) del pontífice en Anagni en septiembre de $1303 .{ }^{76} \mathrm{El}$ incidente, se ha considerado por algunos, supone una autentica reversión de la imagen creada en Canossa tiempo atrás. ¿Se inicia así un proceso de inevitable desgaste de la autoridad papal y de sus procedimientos sancionadores?

Si a la excomunión medieval nos referimos, el problema no es tan sencillo. Pese a la creación de esa doctrina "científicamente elaborada» de la que se ha hablado, el discurso sobre la excomunión no dejó de presentar lagunas y contradicciones ya desde sus mismos orígenes. No es ya tanto por la variedad de términos que se empleen, a la hora de sancionar a un pecador con la exclusión de la comunidad, también porque ya, en fecha tan temprana como el concilio de Nicea, se advierte de los posibles excesos por parte de las autoridades que lanzan una excomunión. ${ }^{77}$ En diversas ocasiones se recuerda que las censuras eclesiásticas deben tener un sentido más «medicinal» que mortal y más correctivo que extirpador, siempre que el que las reciba no las desprecie. ${ }^{78}$

La rutinaria aplicación de ciertas fórmulas imprecatorias del estilo del sit anathema, maranatha (1 Cor. 16, 22), hacen que la excomunión, o la amenaza al menos, pueda adquirir un sentido laxamente preventivo. Una medida de excepcionalidad para sancionar graves delitos como la herejía, acaba siendo utilizada (ya lo advertía un personaje tan poco sospechoso como Pedro Damiani a mediados del siglo XI) para castigar otros de menor calado. Basta con remitirnos a algunos concilios celebrados en territorio ibérico para ver que la excomunión y sus variantes se esgrimen contra muy diferentes transgresiones: concubinato eclesiástico, quebrantamiento del ayuno en las fechas fijadas por la Iglesia, incumplimiento de la confesión y comunión anual tal y como fijaba

\footnotetext{
${ }^{76}$ Sobre este tema resulta aún útil el dossier recogido por Wood, C. 1968. Felipe el Hermoso y Bonifacio VIII. México: UTEHA. Mucho mas reciente es la monografía de Paravicini Bagliani, A. 2003. Boniface VIII: un pape hérétique. Paris: Biographie Payot. El choque del monarca francés y el pontífice tomado como paradigma de las difíciles relaciones entre los dos poderes lo trata Menache, S. 2008. «Iglesia y monarquía en la Edad Media tardía: conflictos y semejanzas», Acta historica et archaeologica mediaevalia 29: 497-516.

${ }^{77}$ «Cánones del concilio de Nicea. Can 5», en Ortiz de Urbina, I. 1963. Nicea y Constantinopla: 263. Vitoria: Editorial ESET.

${ }^{78}$ Vid. por ejemplo «Concilio de Tarragona 1291 (1292) Can. V» en J. Tejada y Ramiro. 1859: t. III: 413. Sobre esa relación mística entre curación física y sanación espiritual vid. el interesante librito de Borobio, D. 2008. Sacramentos y sanación. Dimensión curativa de la liturgia cristiana. Salamanca: Ediciones Sígueme.
} 
el IV Concilio de Letrán, trapicheos en la obligatoriedad del diezmo o (el viejo espíritu de las Asambleas de paz y tregua de Dios) atentados contra personas consagradas a Dios o contra los bienes de la Iglesia: «raptores, invasores, destructores y ladrones de los bienes de las iglesias o de los clérigos y vasallos de las iglesias». ${ }^{79}$

Las excomuniones de mayor impacto - de un pontífice contra un monarca- se tendieron a resolver, además, de forma pragmática. El affaire Canossa y sus secuelas puede considerarse, por su dramatismo, casi una excepción. ${ }^{80}$ Avanzado el siglo XIV las excomuniones contra príncipes pueden convertirse en algo inane si tenemos en cuenta que con el largo Cisma de Occidente (1378-1417) un monarca excomulgado por uno de los dos -o tres- sedicentes pontífices puede contar con el apoyo absolutorio del papa rival al que ha prestado obediencia. ${ }^{81}$

A niveles más bajos, los enfrentamientos y reclamaciones, a propósito del uso y abuso de sanciones del tipo excomunión, serán harto frecuentes ${ }^{82}$ Dos ejemplos pueden resultar ilustrativos. Entre 1200 y la Reforma, F. Donald Logan ha presentado una Inglaterra, con record en el Occidente europeo, en cuanto a excomuniones y reclamaciones de los obispos contra los contumaces en el error. ${ }^{83}$ Por los mismos años en Castilla asistimos a un forcejeo similar entre los dos poderes: de ello hablan las diversas quejas de los procuradores de las ciudades, con motivo de la pérdida de influencia de la jurisdicción regia, dadas las numerosas intromisiones de los jueces eclesiásticos en ella. ${ }^{84}$

Los estudiosos, interesados por el mundo de las ideas, han puesto su foco de atención en ciertos autores de enorme talla intelectual y de nada desdeñable

${ }^{79}$ «Concilio de Alcalá de 1347. can. II», en Tejada y Ramiro, J. 1859: 592

${ }^{80}$ No sólo se utilizará la vía del pragmatismo en la liquidación del contencioso surgido del enfrentamiento entre Tomás Becket y Enrique II, sino también en otro problema coetáneo; el creado por el enfrentamiento entre Federico I Barbarroja -soporte de tres antipapas Víctor IV, Pascual III y Calixto III- y el papa legítimo Alejandro III. Un autentico cisma imperial iniciado en 1159 y que acabó con un arreglo entre los dos rivales en la conferencia de Venecia de 1177. Cardini, F. 1987. Barbarroja. Vida, triunfos e ilusiones de un emperador medieval: 249-252. Barcelona: Ediciones Península.

${ }^{81}$ Para el tema del cisma vid. entre otros muchos aportes, la reciente síntesis de Millet, H. 2009. L'Église du Grand Schisme, 1378-1417. París: Éditions Picard.

${ }^{82}$ Vodola ha hablado de una auténtica «guerra de guerrillas» entre los tribunales laicos y eclesiásticos a fines del Medievo. Vodola, E. 1986: 140-145.

${ }^{83}$ En este período se darán en territorio británico unas diecisiete mil excomuniones de las que habrá más de siete mil reclamaciones (ssignifications) de los obispos a la cancillería real para que procediera al arresto del sancionado que se mantiene contumaz. Donald Logan, F. 1968. Excommunication and the secular arm in medieval England: A study in legal procedure from the Thirteenth to the Sixteenth century. Studies and Texts. Vol. 15. Toronto: PIMS.

${ }^{84}$ Vid. el reciente trabajo de Arranz, A. 2010: «Excomunión eclesiástica y protesta ciudadana, «El conflicto en escenas. La pugna política como representación en la Castilla bajomedieval, J. M. Nieto (coord.): 247-278. Madrid: Sílex. 
incidencia social. Aun admitiendo la legitimidad de severas medidas contra determinados pecados, cuestionaron de manera, mas o menos racional y de forma mas o menos radical, algunos de los procedimientos de exclusión de la comunión de los fieles de los que los papas habían hecho generoso uso.

Resulta cómodo, a más de obligado, recurrir a dos figuras de la primera mitad del siglo XIV, muy críticos con la teocracia pontificia. Marsilio de Padua sostuvo que la excomunión no debía ser resultado de la iniciativa «de un papa, un obispo o un sacerdote» sino de la «universalidad de los fieles», o de un juez instruido por esa misma comunidad. ${ }^{85}$ Para Guillermo de Ockham los poderes de «atar y desatar» otorgados a Pedro habría que interpretarlos con prudencia. El modelo sería el propio Jesús en su reconvención a quienes querían castigar a la mujer sorprendida en adulterio (Jn. 8, 4), o cuando templó la ira de Santiago y de Juan contra los samaritanos (Lc. 9, 51-56). ${ }^{86}$

No es casual que estos dos autores participaran de una línea de pensamiento que reivindicaba el papel del Concilio frente a las ínfulas autoritarias de los papas. El conciliarismo es un movimiento complejo, de profundas raíces en el pensamiento eclesiológico medieval. ${ }^{87}$ En la Baja Edad Media adquirió distintos matices. Lo hubo de naturaleza revolucionaria, marcado por la influencia de los dos autores antes citados, pero también templada. Sería el caso de Jean Gerson, teólogo, místico y canciller de la universidad de París, quien, en 1417, en su Tratado sobre la potestad eclesiástica, sostenía que la excomunión se podía aplicar a «cismáticos pertinaces, heréticos y otros viciosos incorregibles». Para los atentados contra los bienes eclesiásticos bastaría con penas pecuniarias. Conciliarista moderado lo sería también el representante castellano en Basilea, Alonso de Cartagena, quien, tras abiertos escarceos con las posiciones más avanzadas, se manifestaría, al final, a favor del mantenimiento de ciertas prerrogativas pontificias ${ }^{88} \mathrm{Y}$ habría también un conciliarismo puramente pragmático como el del canciller y cronista castellano Pero López de Ayala, quien -recor-

\footnotetext{
${ }^{85}$ Marsilio de Padua. 1988. El defensor de la paz: 186.L. Martínez Gómez (ed.) Madrid: Tecnos.

${ }^{86}$ Guillermo de Ockham. 1992. Sobre el gobierno tiránico del papa: 54 y ss. y 71-72. P. Rodríguez Santidrián (ed.) Madrid: Tecnos

${ }^{87}$ Sobre la formación de esta doctrina es una clásico universalmente reconocido. Tierney, B. 1955. Foundations of the Conciliar Theory. The contribution of the Medieval canonists from Gratian to the Great Schism. Cambridge: University Press, edición ampliada en 1997. También digno de mención, 1976. Die Entwicklung des Konziliarismus. Werden und Nachwirken der konziliaren Idee, R. Bäumer (Hrsg). Darmstadt: Herder.

${ }^{88}$ Fernández Gallardo, L. 2002. Alonso de Cartagena. Una biografia política en la Castilla del siglo $X V .163-167$. Valladolid: Junta de Castilla y León, Consejería de Educación y Cultura. Sobre la posición de los españoles ante la crisis conciliar vid, también la panorámica de Goñi Gaztambide, J. 1978. «El conciliarismo en España», Scripta Theologica X: 893-927, o las monografías de Suárez Fernández, L. 1960. Castilla, el cisma y la crisis conciliar (1378-1440). Madrid: Consejo Superior de Investigaciones Científicas, y Álvarez Palenzuela, V. A. 1992. La situación europea en época del Concilio de Basilea. Informe de la delegación de Castilla. León: Centro de Estudios e Investigaciones San Isidoro.
} 
dando los Concilios toledanos de época visigótica- defendía este instrumento para liquidar el Gran Cisma de Occidente. ${ }^{89}$ Significativo sería el caso de un ferviente conciliarista en su juventud, como Eneas Silvio Piccolomini que, una vez llegado a Papa -Pío II, entre 1458 y 1464- renegaría de estos principios y se manifestaría partidario de aplicar la excomunión en distintas ocasiones. «Olvidaos de lo que dijo Eneas, acatad lo que ahora dice Pío», resume bien el giro palinódico del personaje. ${ }^{90}$

\section{DOS EXCOMUNIONES PARA DOS GRAVES RUPTURAS}

Pese a que la capacidad de excomunión queda en manos de distintos escalones de dignatarios de la Iglesia, las excomuniones papales, por razones obvias, son las que socialmente resultan más conocidas. A veces las únicas.

Se ha dicho que la excomunión mutua de las iglesias de Roma y de Constantinopla en 1054 -cisma de Oriente, o, en el lenguaje mas conciliar, cisma grecolatino- tuvo unos efectos similares a los provocados por la rebelión de Lutero en $1517,{ }^{91}$ causa, a medio plazo, de su excomunión a fines de 1520. La primera rompió la unidad de las Iglesias de Oriente y Occidente que, pese a intentos posteriores de reconciliación, no se logró recomponer. ${ }^{92}$ La segunda, provocaría el «éxodo de la mitad de la cristiandad occidental»; en esencia la Europa nórdica y buena parte de la centra..$^{13}$

Por tanto, en el amplio ámbito cronológico en el que nos hemos desenvuelto, estas dos excomuniones tendrían (perdónesenos el desenfadado lenguaje) un «rotundo éxito» en lo que a exclusión del otro se refiere. Una gran diferencia con los resultados de las otras muchas que se dieron a lo largo del Medievo y que se solventaron repetidas veces por la vía de la transacción entre las partes.

\footnotetext{
${ }^{89}$ López de Ayala, Pero. 1978. Libro rimado de Palaçio, Joset, J. (ed.). Vol 1: 305. Madrid: Clásicos Alhambra. También vid. Strong, E. B. 1961. «The Rimado de Palacio: Lopez de Ayala's Proposals for ending the Great Schism», Bulletin of Hispanic Studies XXXVIII: 64-77.

${ }^{90}$ Pío II, 1989.: Así fui papa: 287. (Traducción y adaptación de los Comentarii del personaje, por parte de A. Castro Zafra). Madrid: Argos Vergara.

${ }^{91}$ Obolensky, D. 1977. «La Iglesia bizantina», Nueva Historia de la Iglesia. II La Iglesia en la Edad Media, D. Knowles y D. Obolensky (dir.): 122. Madrid: Ediciones Cristiandad.

${ }^{92}$ Entre las obras sobre las turbulentas relaciones entre Oriente y Occidente en el Medievo esta la ya clásica de Dvornik, F. 1968. Bizancio y el primado romano. Bilbao: Desclée de Brouwer.

${ }^{93}$ Strohl, H. 1962. Luther jusqu'en 1520: 380. París: Presses Universitaires de France.
} 


\section{FUENTES}

Burchardus Wormatiensis: Decretum, Patrologia Latina CXL cols 857-969.

Catecismo de la doctrina cristiana escrito por el P. Gaspar Astete de la Compañía de Jesús. Dispuesto en orden cíclico: 22. (Decimaoctava edición). Valladolid.

Código de Derecho Canónico: 601 Madrid: Conferencia Episcopal Española.

«Concilio de Ancira», Colección de cánones y de todos los concilios de la Iglesia de España y de América, vol 1: 40. (J. Tejada y Ramiro, editor). 1859. Madrid: Imprenta de D. Pedro Montero.

Concilio de Coyanza era 1088» tit. IV, Tejada y Ramiro. J. 1859: vol. III, 97.

Concilio de Elna» (Tambien llamado Tulujense) año 1027, en Tejada y Ramiro, J. 1849-1855. Coleccion de cánones de todos los concilios de la Iglesia de España y América: vol. III, 83. Madrid

Cánones del concilio de Nicea», en Ortiz de Urbina, I. 1969, Nicea y Constantinopla: 263 Vitoria: ESET.

Can., XV del «Concilio de Braga I», 1963. Concilios visigóticos: 74 y en Cánones XXXVII y LXXXIV del «Concilio de Braga II», ibídem: 106.

«Concilio de Alcalá de 1347. can. II», en Tejada y Ramiro, J. 1859: 592

«Concilio de Tarragona 1291 (1292) Can. V» en J. Tejada y Ramiro. 1859: t. III: 413.

«Concilio de Salamanca de 1192» III: 295.300, Tejada y Ramiro, J. 1859.

Can., V de «Concilio de Zaragoza I», 1963. Concilios visigóticos: 17

Concilios visigóticos e hispanorramnos: 6 y Santa Sede. (Ed. de J. Vives, G. Martínez Diez y T. Marín ). 1963. Barcelona-Madrid: Instituto Enrique Flórez, CSIC.

Constituciones de Clarendon. Cap. VII», en Stubbs, W. 1884. Selects Charters and other Illustrations of English Constitutional History: 137-140. Oxford: Clarendon Press.

«Decretos del Primer Concilio de Letrán» can. 2, en Foreville. R 1972: 225.

Decretos del III Concilio de Letrán», decr. 6, en ForevilLe, R.: Lateranense I, II y III, p. 268-269.

«Decretos del IV Concilio de Letrán»1. De la fe católica. Recogido en Foreville, R. 1972. Lateranense IV: 156. Vitoria: ESET.

«Decretos del IV Concilio de Letrán», can . 3 en Foreville, R. 1972: 160

Dictatus Papae, art. 27 de los, recogido entre otros por Gallego Blanco, E. 1973. Relaciones entre la Iglesia y el Estado en la Edad Media: 185. Madrid: Revista de Occidente.

Haeretici diversarum sectarum, dirá en el II Concilio de Lyon. de 1274 el general de los dominicos Humberto de Romans Mansi, G.D. 1780. Sacrorum conciliorum nova et amplissima Collectio 2: 109-110. Venetiis: Apud Antonium Zatta.

Guillermo de Ockham. 1992. Sobre el gobierno tiránico del papa: 54 y ss y 71-72. P. Rodríguez Santidrián (ed.) Madrid: Tecnos

Marsilio de Padua. 1988. El defensor de la paz: 186.L. Martínez Gómez (ed.) Madrid: Tecnos. 
Raimundo de Peñafort: Summa de Poenitentia, cit. 1, III tit. 33 n 9, col. 746. Recogido en Marzoa, A. 1985. La censura de excomunión, Estudio de su naturaleza jurídica. Ss. XIII-XV: 82. Pamplona: EUNSA.

San Cipriano. 1991: La unidad de la Iglesia: 88. Ed. de C. Falla y J Pascual Torro. Madrid, Bogotá, Buenos Aires, México, Montevideo, Santiago: Ciudad Nueva.

Santo Tomás de Aquino: Suplementum a la III pars de la Suma Teológica q. XXI, citado también en Marzoa, A. 1985: 36

Tertuliano: Apologético: 148-149 y. J. Andino (ed). 1997. Madrid: Biblioteca de Patrística.

\section{BiBLIOGRAFÍA}

Abadal, R. d'. 1948. L'Abat Oliba, bisbe de Vic y la seva època. Barcelona: Salva. Hay una reedición. 2003. Pamplona: Urgoiti Editores S.L.

Albareda, A. 1931- L'abat Oliba, fundador de Monstserrat. Assaig biografic. Monestir de Montserrat. 66-85.

Alberigo, G. 1970. «¿Nuevas fronteras en la Historia de la Iglesia?», Concilium: 57:

Álvarez Palenzuela, V. A. 1992. La situación europea en época del Concilio de Basilea. Informe de la delegación de Castilla. León: Centro de Estudios e Investigaciones San Isidoro.

Arranz, A. 2010: «Excomunión eclesiástica y protesta ciudadana «El conflicto en escenas. La pugna política como representación en la Castilla bajomedieval, J. M. Nieto (coord.): 247-278. Madrid: Sílex.

Asenjo, M. 2008 «Integración y exclusión. Vicios y pecados en la convivencia urbana», Pecar en la Edad Media, en Carrasco, A. I. y. Rábade, M. P (coords): 185- 208. Madrid: Sílex Universidad.

Auer, J. 1960. La Iglesia Curso de Teología dogmática: 46-70. Barcelona: Herder.

Alvira, M. 2002. 12 de septiembre de 1213 El jueves de Muret. Barcelona: PPU. Promociones y Publicaciones Universitarias.

Bach, D. 1993. «Anatema», Diccionario enciclopédico de la Biblia: 70-71. Barcelona: Herder.

Barlow, F. 2010 Tomás Becket el santo politico. Barcelona: Edhasa.

Barthelemy, D. 1999.: L'an Mil et la paix de Dieu. París: Fayard.

Barthelemy, D. 2006. Caballeros y milagros. Violencia y sacralidad en la sociedad feudal: 27-30. Univesitat de Valencia-Universidad de Granada 2006.

Belperrie du Bayac, J. 1977. Carlomagno, 287. Barcelona; Ayma.

Bernhard, J. 1965. «Excommunication et pénitence-sacrament aux deux premiers siècles de 1'Eglise. Contribution canonique», Revue de Droit Canonique 15: 265-281, 318-330. 1966. 16: 41-70.

Birou, A. 1964. Sociología y religión: 91. Madrid: Instituto de Estudios Políticos. 
Borobio, D. 2008. Sacramentos y sanación. Dimensión curativa de la liturgia cristiana. Salamanca: Ediciones Sígueme, S. A.

Bouyer, L. 1977: Voz. «Transubstanciación», Diccionario de teología: 631, Barcelona: Ediciones Sígueme.

Brundage, J. A. 1995. Medieval Canon Law: 77. London: Longman.

Cardini, F.. 1987. Barbarroja. Vida, triunfos e ilusiones de un emperador medieval: 249-252. Barcelona: Ediciones Península.

Chelini, J. 1968. Histoire religieuse de l'Occident medieval. Paris: Armand Colin.

Donald Logan, F. 1968. Excommunication and the secular arm in medieval England: A study in legal procedure from the Thirteenth to the Sixteenth century. Studies and Texts. Vol. 15. Toronto: PIMS.

Congar, Iv.-M. 1976. Eclesiología. Desde San Agustín hasta nuestros días: 64-65. Madrid: Biblioteca de Autores Cristianos.

Duby, G. 1973. «Les laïcs et la paix de Dieu», Hommes et structures du Moyen Age: 227-252. París: Flammarion.

Dvornik, F. 1968. Bizancio y el primado romano. Bilbao: Desclée de Brouwer.

Eimeric Nicolau y Peña, Francisco.1983. Manual de inquisidores, Sala Molins, L. y Martín, F. (eds.): 100-102. Barcelona: Muchnik.

Escribano, M. V. 2007. «Formas de violencia contra heréticos en Codex Theodosianus XVI, 5 (De haereticis)» en G. Bravo y R. González Salinero (Eds), Formas y usos de la violencia en el mundo romano. (Actas del IV Coloquio de la Asociación interdisciplinar de Estudios Romanos): 77. Madrid: Signifer Libros.

Fernández Gallardo, L. 2002. Alonso de Cartagena. Una biografía política en la Castilla del siglo XV. 163-167. Valladolid: Junta de Castilla y León, Consejería de Educación y Cultura.

Flori, J. 2010. El Islam y el fin de los tiempos. La interpretación profética de las invasiones musulmanas en la Cristiandad medieval: 163-172. Madrid: Ediciones Akal.

García Gallo, A. 1950-1951: «El concilio de Coyanza», en Anuario de Historia del Derecho Español: número 20: 275-633.

García y García, A. 1967. Historia del derecho canónico I. El primer milenio: 142143. Salamanca: Instituto de Historia de la Teología Española.

Gaudemet, J. 1949. «Les formes anciennes de l'excommunication», Revue des Sciences Religieuses: 23: 64-77.

Gonzalvo, G. 1994. Les constitucions de pau i treva de Catalunya (segles XI-XIII). Barcelona: Departament de Justícia. Generalitat de Catalunya.

Goñi Gaztambide, J. 1978. «El conciliarismo en España», Scripta Theologica X: 893-927.

Head T. y R. Landes, R. (Eds.) 1992. The Peace of God. Social Violence and Religious response in France around the Year 1000. London, Ithaca-New York: Cornell University. 
Johnson, H. M. 1968: «Grupos religiosos», Sociología de la religión y de la moral, en T. Parsons (Ed.): 147 y ss.. Buenos Aires: Paidos.

Kantorowicz, E. 1987. L'empereur Frederic II: 243. Paris: Quarto Gallimard (edición original alemana de 1936).

Küng, H. 1970: La Iglesia: 17 Barcelona: Herder.

Lambert, M. D. 1986. La herejía medieval. Movimientos populares de los bogomilos a los husitas: 116. Madrid: Taurus

Landau. P. 1966. Die Entstehung des kanonischen Infamiebegriffs von Gratian bis zur Glossa ordinaria. Colonia: H. Böhlaus.

López de Ayala, Pero. 1978. Libro rimado de Palaçio: J. Joset (ed). Vol 1: 305. Madrid: Clásicos Alhambra.

Lortz, J. 1962. Historia de la Iglesia desde la perspectiva de la historia de las ideas.1962. Exposición e interpretación histórica del pasado cristiano: 22. Madrid: Ediciones Guadarrama.

Lubac, H. de. 1974. Las iglesias particulares en la iglesia universal: 52-53. Salamanca: Ediciones Sígueme.

Marzoa, A. 1985. La censura de excomunión, Estudio de su naturaleza jurídica. Ss. $X I I I-X V$ : 73. Pamplona: EUNSA.

Menache, S. 2008. «Iglesia y monarquía en la Edad Media tardía: conflictos y semejanzas», Acta historica et archaeologica mediaevalia 29: 497-516

Millet, H. 2009. L'Église du Grand Schisme, 1378-1417. París: Éditions Picard.

Mitre, E. 2005.: «Herejías y sectas; herejías y cismas: la fluctuante tipología del Occidente medieval», Iglesia de la Historia, Iglesia de la fe: 249-265. Homenaje a Juan Maria Laboa Gallego, F. Rivas Rebaque y R. M. Sanz de Diego (eds.) Madrid: Universidad Pontificia de Comillas.

Mitre, E. 2008. «Los pecados desde la herejía: la moral del otro en la Edad Media» Pecar en la Edad Media: 281-295. Madrid: Sílex Universidad.

Mörsdorf, K. 1979: voz «Excomunión» Conceptos fundamentales de la teología, (Dir. H. Fries), t. 1: 536-537. Madrid: Cristiandad.

Obolensky, D. 1977. «La Iglesia bizantina», Nueva Historia de la Iglesia. II La Iglesia en la Edad Media, D. Knowles y D. Obolensky (dir).: 122. Madrid: Ediciones Cristiandad.

O’Donell, C. y Pie-Ninot, S. 2001: Voz «Comunión/Koinomia», Diccionario de Eclesiología: 192 Madrid: Ediciones San Pablo.

Pacaut, M. 1957. La theocratie. L'Eglise et le pouvoir au Moyen Age. París: Aubier

Pascua, E. 1995. «Violencia , escatología y cambio social. La polémica en torno al movimiento de Paz de Dios», Hispania: LV/2 190: 727-737.

Paravicini Bagliani, A. 2003. Boniface VIII: un pape hérétique. Paris: Biographie Payot.

Paul, J. 2003. Historia intelectual del Occidente medieval: 102 Madrid: Cátedra. 
Pérez de Tudela. M. I. 2008.«El concepto de pecado como arma de control político: el matrimonio de Alfonso IX de León y Berenguela de Castilla», Pecar en la Edad Media: 81-96. Madrid: Sílex. Universidad.

Pío II, 1989. Asi fui papa: 287. (Traducción y adaptación de los Comentarii del personaje por parte de A. Castro Zafra). Madrid: Argos Vergara.

Ruiz Doménech, J. E. 2004. «El abad Oliba: un hombre de paz en tiempos de guerra». En Ante el Milenario del reinado de Sancho el Mayor. Un rey navarro para España y Europa (XXX Semana de Estudios Medievales. Estella 2003): 173-196.Pamplona: Departamento de Educación. Gobierno de Navarra).

Sánchez Herrero, J. 2005: Historia de la Iglesia II Edad Media: XIX. Colección Sapientia Fidei. Serie de Manuales de Teología. Madrid: Biblioteca de Autores Cristianos.

Strohl, H. 1962. Luther jusqu'en 1520: 380. París: Presses Universitaires de France.

Strong, E. B. 1961. «The Rimado de Palacio: Lopez de Ayala's Proposals for ending the Great Schism», Bulletin of Hispanic Studies, XXXVIII: 64-77.

Suárez Fernández, L. 1960. Castilla, el cisma y la crisis conciliar (1378-1440). Madrid: Consejo Superior de Investigaciones Científicas.

Taberner, F. 1936. San Ramón de Penyafort: 104-116. Barcelona. Hay una reedición, 1979. San Ramón de Penyafort. Barcelona: Labor.

Tierney, B. 1955. Foundations of the Conciliar Theory. The contribution of the Medieval canonists from Gratian to the Great Schism. Cambridge: University Press, edición ampliada en 1997.

Tuya, M. de y Salguero, J. 1967. Introducción a la Biblia I. Inspiración bíblica. Canon. Texto. Versiones: 291. Madrid: Editorial Católica. Biblioteca de Autores Cristianos.

Vodola, E. 1986. Excommunication in the Middle Age: 28-29 y 34. Berkeley-Los Angeles: University of California Press.

Vogel, C. 1975. «Penitencia y excomunión en la Iglesia antigua y en la Alta Edad Media», Concilium: 107: 9-21.

Wolter, W. y Holstein, W. 1979. Historia de los concilios ecuménicos. Lyon I y Lyon II: 23. Vitoria: Editorial ESET.

Wood, C. 1968. Felipe el Hermoso y Bonifacio VIII. México: UTEHA.

Zimmerman, H. 1975. Der Canossagang von 1077. Wirkungen und Wirklichkeit. Wiesbaden: Franz Steiner Verlag.

1976. Die Entwicklung des Konziliarismus. Werden und Nachwirken der konziliaren Idee, R. Bäumer (Hrsg). Darmstadt: Herder.

2006. La reforma gregoriana y su proyección en la cristiandad occidental. Siglos XI-XII. Actas de la XXXII Semana de Estudios Medievales (Estella 2005). Pamplona: Gobierno de Navarra, Institución Príncipe de Viana. 